\title{
Processing of high-grade zeolite nanocomposites from solid fuel combustion by-products as critical raw materials substitutes
} \author{
and Margarita Popova ${ }^{2}$ \\ 1 Technical University of Sofia, Sofa, Bulgaria \\ ${ }^{2}$ Institute of Organic Chemistry with Centre of Phytochemistry, BAS, Sofia, Bulgaria \\ ${ }^{3}$ Institute of Optical Materials and Technologies "Acad. J. Malinowski", BAS, Sofia, Bulgaria \\ ${ }^{4}$ Institute of Nanostructure Technologies and Analytics, University of Kassel, Kassel, Germany
}

Silviya Boycheva ${ }^{1, *}$, Denitza Zgureva ${ }^{1}$, Hristina Lazarova ${ }^{2}$, Katerina Lazarova ${ }^{3}$, Cyril Popov ${ }^{4}$, Tsvetanka Babeva ${ }^{3}$,

Received: 7 December 2019 / Accepted: 28 May 2020

\begin{abstract}
High-grade zeolite nanocomposites are synthesized utilizing solid by-products from combustion of coal for energy production in Thermal Power Plants applying alkaline aging, hydrothermal and fusionhydrothermal activation procedures. The obtained coal ash zeolites were studied with respect to their chemical and phase composition, morphology, surface parameters and thermal properties. It was found that they are distinguished in nanocrystalline morphology and significant content of iron oxide nanoparticles $\left(\gamma-\mathrm{Fe}_{2} \mathrm{O}_{3}\right.$, $\left.\alpha-\mathrm{Fe}_{2} \mathrm{O}_{3}, \gamma-\mathrm{Fe}_{3} \mathrm{O}_{4}\right)$ and doping elements $(\mathrm{Cu}, \mathrm{Co}, \mathrm{Mn}, \mathrm{V}, \mathrm{W}$, etc.) transferred from the raw coal ash, and therefore they are assumed as nanocomposites. Coal fly ash zeolite nanocomposites are characterized by a mixed micro-mesoporous texture, significant concentration of acidic Brønsted centers due to their high surface insaturation, high chemical and thermal stabilty. This unique combination of compositional and textural properties predetermines the application of these materials as catalysts for thermal oxidation processes, anticorrosion barrier coatings, carbon capture adsorbents, matrices for hosting functional groups, detergents etc. Examples for coal fly ash zeolite applications for substitution of critical raw materials in practice are provided.
\end{abstract}

Keywords: Coal ash utilization / fly ash zeolites / nanocomposites / critical raw materials

\section{Introduction}

The era of coal energy production has not passed, despite the progress of the renewable energy technologies due to the sustainability and scale of energy production. According to the market analysis and forecasts, the global coal demand in the next five years is set to be stable, and the consumption of coal is increased by $1 \%$ in 2017 to $7585 \mathrm{Mt}$ as compared to the previous year due to the strong global economic growth associated with increased electricity consumption [1]. Coal provides $27 \%$ of the global primary energy needs and generates roughly $41 \%$ of the world's electricity. In 2018, the coal consumption of the European Union (EU), including hard coal and brown coal, have reached $596 \mathrm{Mt} \mathrm{[2].} \mathrm{It} \mathrm{is} \mathrm{expected} \mathrm{that} \mathrm{global}$ coal production will keep importance, supplying around $44 \%$ of the global electricity at least up to 2030 , while in the EU the share of the produces energy from coal will be reduces but it will keep serious position $[1,3]$. In addition,

\footnotetext{
* e-mail: sboycheva@tu-sofia.bg
}

the concept of zero-emission coal supplied TPPs is being developed intensively due to the increase in the innovation level of the environmental protection facilities [4,5]. However, coal combustion generates huge quantities of solid wastes, which are fly ash, bottom ash, boiler slag, fluidised bed combustion ash, and flue gas desulphurization products. In the EU approximately $40 \mathrm{Mt}$ coal combustion by-products are yearly produced. Within the EU, the utilization of fly ash in the construction industry is around $43 \%$, for bottom ash is roughly $46 \%$ and $100 \%$ for boiler slug [6]. Coal fly ash (CFA) is mainly utilized for production of blended cement, as a concrete addition, in concrete blocks, and in road construction. The advanced applications of this abundant resource do not exceed $4 \%$ from the total utilized amounts [6]. The beneficial use of coal fired power plant by-products is of main concern imposed in the EU legislation [3]. Large amounts of fly ash are landfilled in EU or used for low-value applications because of the lack of sufficient developments to utilize smartly this abundant resource of raw materials which useful potential is not fully discovered yet. The reasonable use of coal ash wastes will contribute to a number of 
environmental benefits such as: improved ecology and economy of the thermal power plans, saving natural resources and reduction of landfills. However, the utilization of CFA is not an easy task because it is one of the most complex in chemical and phase composition wastes, especially when high technological and environmentally friendly applications are targeted $[7,8]$. CFA is specified in two classes $\mathrm{F}$ and $\mathrm{C}$ according to the international standard ASTM C618 regarding its chemical composition from the point of view of the suitability of this raw material for production of cement [9]. Smart utilization of coal fly ash is the processing of zeolites by alkaline conversion processes $[10,11]$. CFA-based zeolites with a controllable size of the constituent crystallites of the order of nanosizes and with a uniform distribution of the metal oxide phases transferred into the zeolite matrix from the raw ash as nanoparticles can be considered as nanocomposites unlike their pure synthetic analogies. In general, zeolites are microporous aluminosilicate materials of natural or synthetic origin of extreme practical importance as adsorbents, dryers, molecular sieves, ionexchangers, catalytic carriers, etc. [12]. However, the potential of these materials is not fully exploited beyond their traditional applications. By managing their morphology to nanoscales or modifying them with additives and fillers, they become valuable materials for sensing devices, photocatalysts, solar thermal collectors, photovoltaic energy conversion systems, optoelectronics, smart coatings, preparation of functional host-guest materials $[13,14]$.

Meanwhile, a new group of materials has been identified on the basis of economic criteria and importance for the existence and development of strategic industries in EU, so called critical raw materials (CRMs). CRMs are key materials for the sustainable functioning of the European economy, as they concern production of steels and highvalue alloys for energetic, transport, machinery, telecommunications, green technologies, aerospace and aviation, medical tools, micro-electronic devices, defence equipment, and many other high-technology products. Because of the high risk of their supply due to the import dependence of non-European countries, these materials are critical to ensuring the long-term sustainability of life, health and safety of the European citizens. At present, twenty six raw materials and groups have been assessed as critical for EU, such as Sb, Be, Bi, Co, Ga, Ge, Hf, He, In, $\mathrm{Mg}, \mathrm{Nb}, \mathrm{Sc}, \mathrm{Si}, \mathrm{Ta}, \mathrm{V}, \mathrm{W}, \mathrm{P}$, barite, borate, phosphate rock, natural graphite, natural rubber, fluorspar, the group of heavy-rare earth elements (Dy, Er, Eu, Gd, Ho, Lu, Tb, $\mathrm{Tm}, \mathrm{Yb}, \mathrm{Y})$, the group of light-rare earth elements (Ce, La, $\mathrm{Nd}, \mathrm{Pr}, \mathrm{Sm}$ ), and platinum group materials (Ir, Pt, Pl, Rh, $\mathrm{Ru}$ ) [15].The strategies for overcoming the CRMs problem foresee savings in raw materials by optimizing processes, discovering of new sources, recycling, and finding alternatives to substitute them with analogues. However, the development of substitutes is a very big challenge because of the unique properties of CRMs $[16,17]$. Due to their thermal stability, resistance to chemicals, radiation and oxidation, lack of corrosion and the absence of disposal problems because of their harmlessness and environmental compatibility, zeolites could be preferable materials to replace successfully some critical raw materials in catalysts, coatings and detergents [18].

This study is aimed at smart utilization of fly ash from coal by its conversion to zeolite-based nanocomposites in terms of their applications for substitution, recovery and use reduction of CRMs. The present paper summarizes the best our achievements on the zeolitization of coal fly ash and provides results on the characterization of zeolite nanocomposite samples with potential use in CRMs substitution.

\section{Processing of coal ash zeolite nanocomposites}

For the synthesis of zeolite-based nanocomposites three technological schemes are most often applied, so called double-stage fusion-hydrothermal synthesis (FH), hydrothermal activation (HA) and atmospheric aging (AA) [19]. The technological stages of the three approaches are presented in Figure 1. The thermal conditions and alkalinity reported here are optimal for processing of Faujasite zeolite type (FAU; Na-X) [20]. However, different zeolite phases can be achieved by varying the temperature and duration of the hydrothermal activation, the type of the alkaline activator and its ratio against the CFA amount [10]. The alkaline conversion of CFA to zeolites is consisting of dissolution of the aluminosilicate components from the raw material in alkaline media, formation of hydrogel and its subsequent heterogeneous crystallization onto the insoluble particles [21]. The homogenization of the reaction mixtures by ultrasonic treatment instead of magnetic stirring results in nanocrystalline morphology of CFAZ obtained [22]. Processing of CFAZ by the FH method leads to the highest yield of the zeolite phase in the final product due to the alkaline dissolution of the total aluminosilicate constituents in the CFA composition, even the most resistant ones, such as Quartz, Anorthite and Mullite, stipulated by the solidliquid interactions between the CFA components and the alkaline activator during the fusion stage. At the other synthesis approaches HA and AA the crystalline phases from the raw CFA remain unconverted in the final products, as the zeolite structures are obtained mainly from the amorphous part. The highest zeolitization yield of zeolite FAU achieved at the FH processing of CFAZ is $95 \mathrm{wt} . \%$ in regard to the starting aluminosilicate part of the CFA. Applying HA and AA technological approaches up to $55 \mathrm{wt} . \%$ of zeolite phase in the products was established. CFAZ can be deposited hydrothermally as thin film coatings onto different surfaces by directing crystallization from the reaction volume to the substrates by a temperature gradient [23,24].

\section{Characterization of raw coal fly ash and coal fly ash zeolite nanocomposites}

CFA and CFAZ nanocomposites were characterized by scanning electron microscopy (SEM) regarding their morphology. Typical SEM images obtained by a scanning 


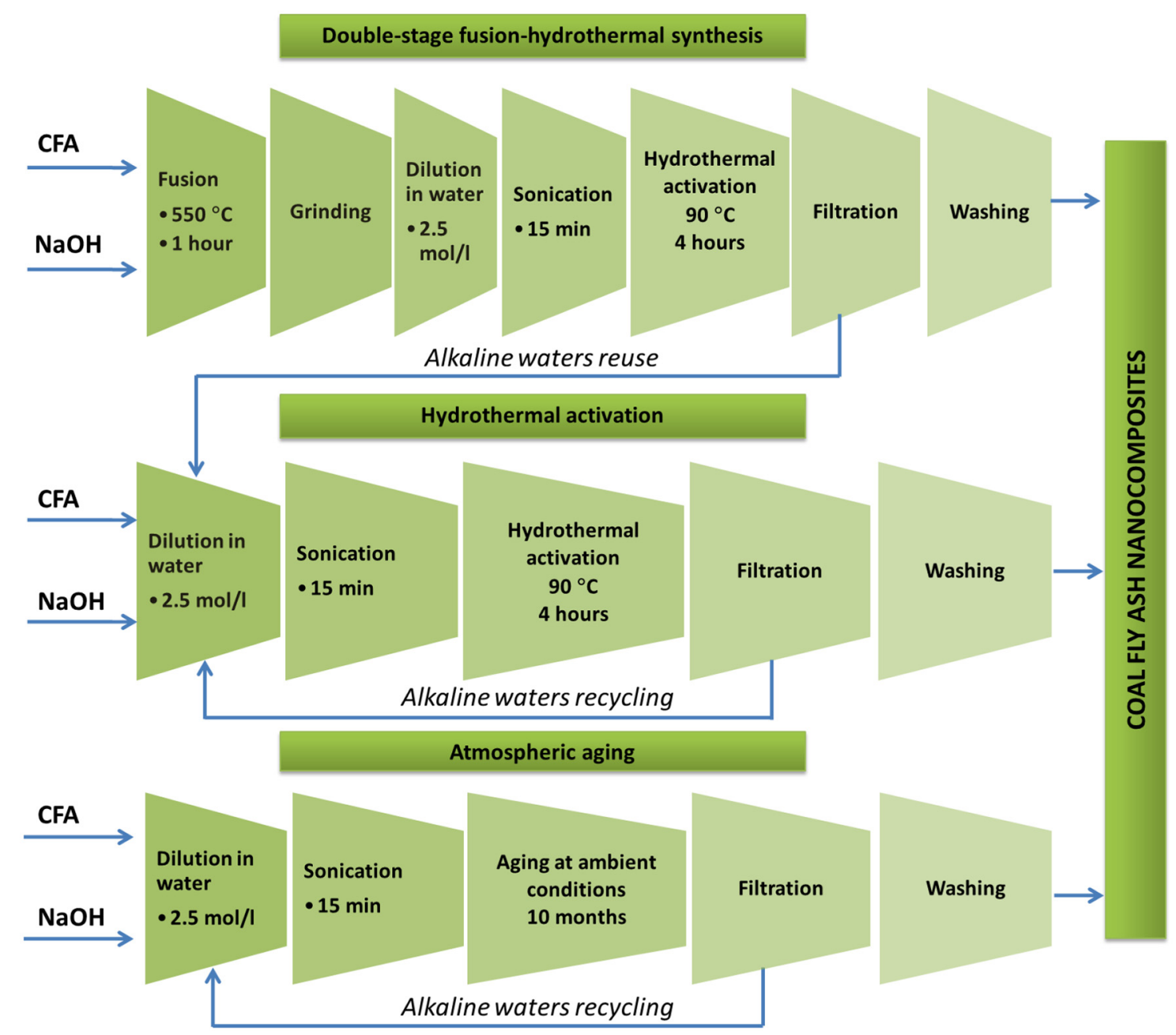

Fig. 1. Technological flow-chart for synthesis of zeolite-based nanocomposite from coal fly ash.

electron microscope ZEISS EVO 25 LS equipped with EDAX Tident spectrometer at acceleration voltage of 20 $15 \mathrm{kV}$, electron beam current of 500-150 pA are presented in Figure 2.

The raw CFA is composed of microparticles with varying morphology (Fig. 2a,b). SEM images reveal nanocrystalline texture for the CFAZ synthesized by $\mathrm{FH}$ method, while for the samples prepared by HA and AA crystallites with sizes around 1-2 $\mu \mathrm{m}$ were observed. FHA samples are usually composed of a particular zeolite phase (Fig. 2c,d). Zeolites obtained by HA treatment of CFA in most cases consist of a basic zeolite phase and one or more accompanying ones. In Figure 2e,f three shapes of zeolitic crystallites can be found, such as hexaoctahedral species typical for zeolite of FAU type, cubic crystals of zeolite Linde type (LTA) and spherical formations which are most likely Sodalite (SOD).

The phase compositions of the raw CFA and the zeolitization products are studied by X-ray diffraction. Experimental diffractograms of CFA and typical for zeolite FAU type synthesized by different technological approaches obtained by using an apparatus Bruker D8 Advance diffractometer (Bruker AXS GmbH, Germany) with $\mathrm{CuK} \alpha$ radiation are presented in Figures 3 and 4 , respectively. Reference diffractograms of crystalline phases are plotted for comparison. The raw CFA is generally characterized by a mixed amorphouscrystalline structure, as the main crystalline phases usually observed are Quartz, Anorthite, Mullite, Gypsum, Hematite and Magnetite [25]. The amorphous part is composed of aluminosilicates and iron ions could be also incorporated.

The elemental analysis of CFAZ is performed by Inductively Coupled Plasma Mass Spectrometry (ICPMS). The content of micro- and trace components in CFAZ obtained by different synthesis procedures are measured by an apparatus ICP-MS Agilent 7700 summarized in Table 1. CFAZ besides their main constituents $\mathrm{Al}, \mathrm{Si}$ and $\mathrm{Na}$, contain significant amounts of $\mathrm{Fe}$ and $\mathrm{Ca}$ transferred from the raw material, but also a big variety of trace elements. The zeolites prepared from coal ash wastes contain elements from the group of CRMs, such as Ce, Co, La, $\mathrm{Mg}, \mathrm{Sc}, \mathrm{V}, \mathrm{Y}$ and $\mathrm{Yb}$ which total content reaches about 5 wt. \% from the CFAZ. The all samples listed in Table 1 are prepared from one and the same starting CFA composition. It could be concluded that the synthesis manner does not 


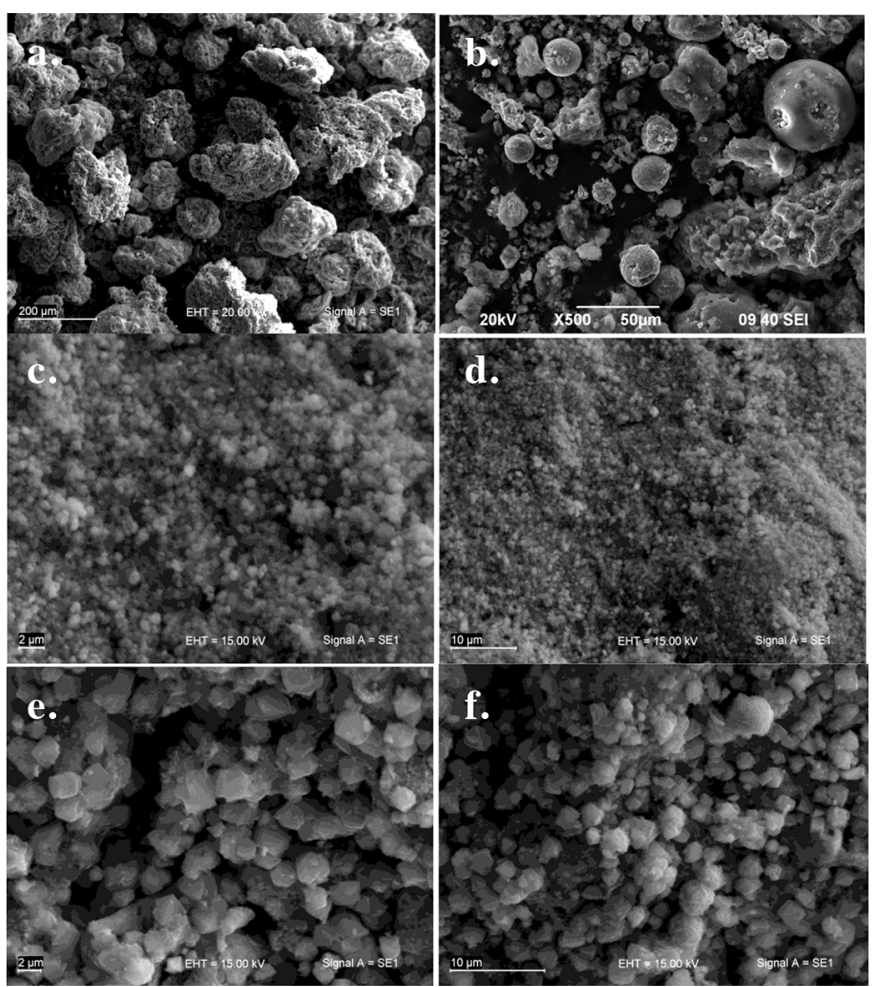

Fig. 2. SEM images of raw CFA and zeolites synthesized from coal fly ash in different magnifications: CFA (a,b) CFAZ synthesized by $\mathrm{FH}$ technique (c,d); CFAZ synthesized by HA technique $(e, f)$.

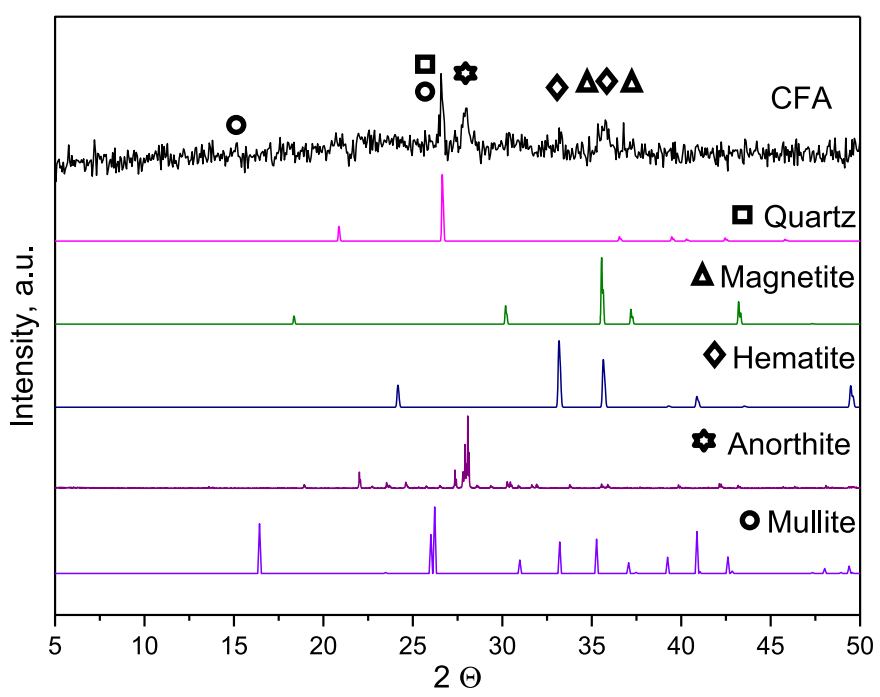

Fig. 3. Experimental diffractogram of raw CFA.

influence the transfere of the CRMs from the CFA to the zeolitization products, except for Co which is present in greater quantity in the sample prepared by atmospheric aging.

CFAZ were characterized with respect to their surface properites, as key parameters related to their practical

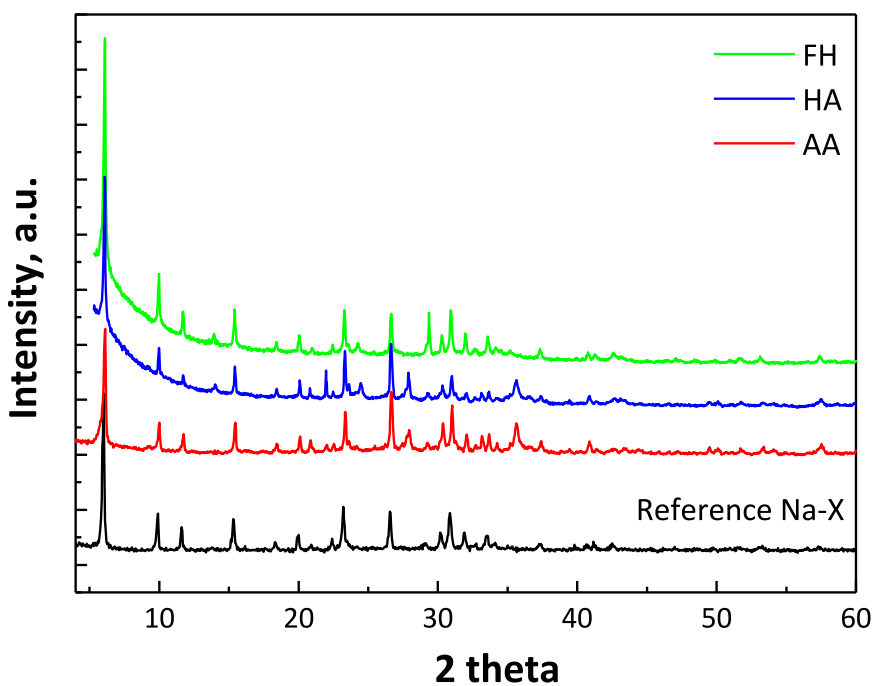

Fig. 4. Experimental diffractograms of zeolite FAU obtained by different synthesis approaches.

Table 1. Micro- and trace elemental composition of coal ash zeolites.

\begin{tabular}{lrrr}
\hline \multirow{2}{*}{ Element } & \multicolumn{3}{c}{ Composition, ppm } \\
\cline { 2 - 4 } & $\mathrm{HA}$ & $\mathrm{AA}$ & \multicolumn{1}{c}{$\mathrm{FH}$} \\
\hline $\mathrm{Fe}$ & 81,550 & 83,501 & 72,256 \\
$\mathrm{Na}$ & 35,579 & 36,343 & 66,149 \\
$\mathrm{~B}$ & 49 & $<300$ & 910 \\
$\mathrm{Ba}$ & 762 & 724 & 688 \\
$\mathrm{Ca}$ & 35,140 & 34,559 & 28,752 \\
$\mathrm{Ce}$ & 94 & 89 & 86 \\
$\mathrm{Co}$ & 38 & 331 & 45 \\
$\mathrm{Cr}$ & 75 & 72 & 55 \\
$\mathrm{Cu}$ & 219 & 245 & 182 \\
$\mathrm{~K}$ & 7521 & 7694 & 6945 \\
$\mathrm{La}$ & 40 & 46 & 43 \\
$\mathrm{Li}$ & 99 & 73 & 116 \\
$\mathrm{Mg}$ & 13,435 & 12,576 & 11,386 \\
$\mathrm{Mn}$ & 545 & 533 & 452 \\
$\mathrm{Mo}$ & 78 & 476 & 27 \\
$\mathrm{Ni}$ & 164 & 319 & 378 \\
$\mathrm{P}$ & 233 & 347 & 49 \\
$\mathrm{~S}$ & 1065 & 1021 & 2406 \\
$\mathrm{Sc}$ & 19 & 18 & 19 \\
$\mathrm{Sr}$ & 543 & 528 & 476 \\
$\mathrm{Ti}$ & 3863 & 3386 & 3645 \\
$\mathrm{~V}$ & 123 & 123 & 14 \\
$\mathrm{Y}$ & 30 & 29 & 31 \\
$\mathrm{Yb}$ & 3 & 3 & 3 \\
$\mathrm{Zn}$ & 71 & 68 & 103 \\
$\mathrm{Zr}$ & & & 105 \\
\hline & & & \\
& & &
\end{tabular}




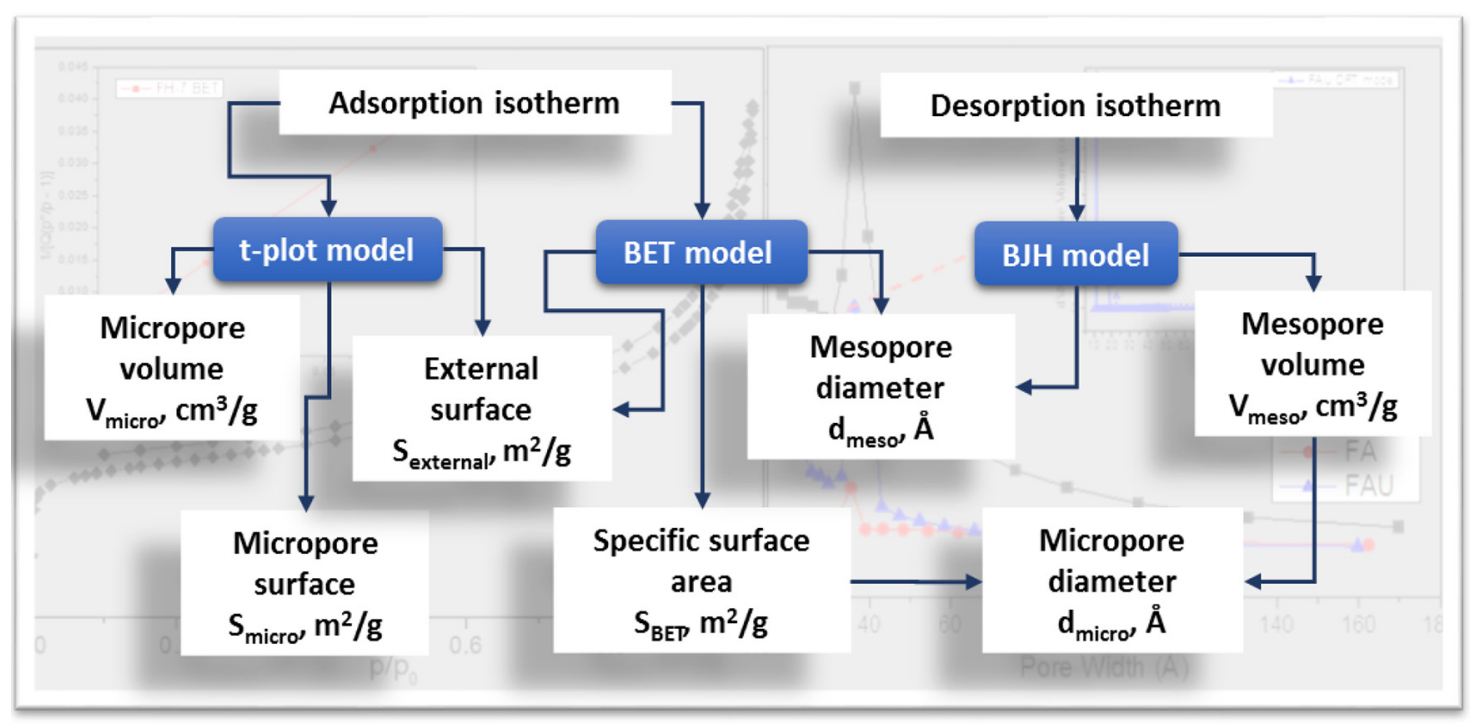

Fig. 5. The main surface characteristics and mathematical models for their computation.

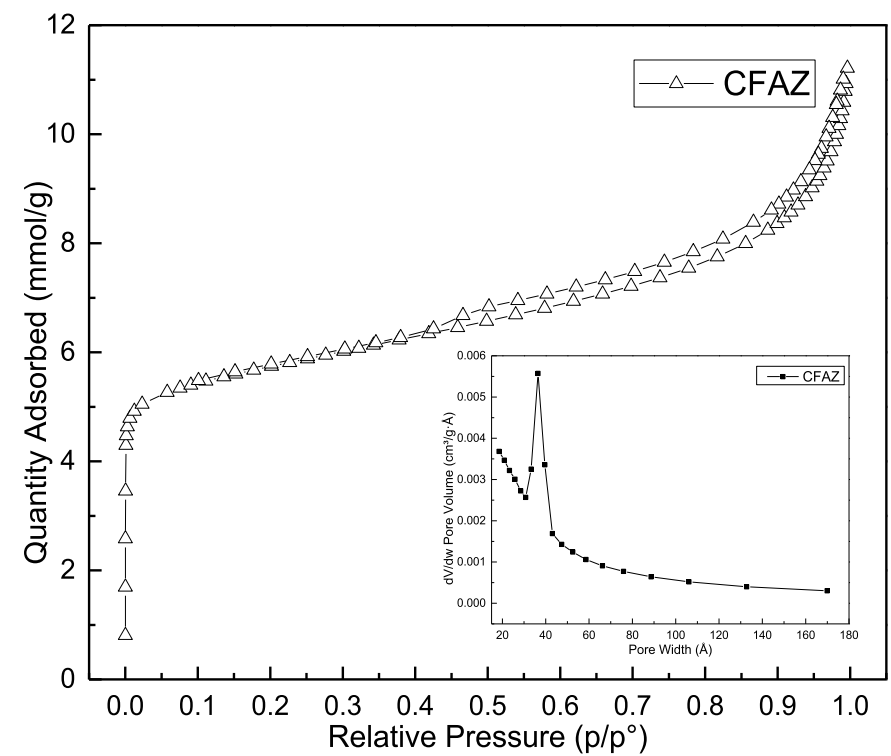

Fig. 6. BET isotherm and BJH-distribution function typical for CFAZ nanocomposite.

applications. For this porpose, experimental $\mathrm{N}_{2}$-physisorption isotherms were measured at cryogenic temperatures $(77 \mathrm{~K})$ ensured by applying liquid nitrogen as a cooler. A volumetric adsorption analyzer Tristar II 3020, Micromeritics was used for the measurements. CFAZ samples were preliminary degassed in a FlowPrep 60, Micromeritics apparatus at $260^{\circ} \mathrm{C}$ for $4 \mathrm{~h}$ under helium flow. The main surface characteristics were computed by standardized mathematical models using the experimental $\mathrm{N}_{2^{-}}$ adsorption/desorption data as input parameters. The relation between surface characteristics, mathematical models for their determination and the input data required are presented in Figure 5. Typical $\mathrm{N}_{2}$-adsorption/desorption isotherm and mesopore size distribution function of CFAZ nanocomposites are plotted in Figure 6.
The presented isotherm can be classified as type IV, according to IUPAC classification (1985) with H3 type hysteresis loop typical for micro-mesoporous texture of the studied materials. The mixed micro-mesoporosity is substantial advantage for CFAZ nanocomposites related to their applications because it facilitates mass-transport phenomena favoring the rate of adsorption, reducing the energy demands for desorption processes and allowing the zeolite frameworks to host large molecules. The surface characteristics of highly zeolitizied CFAZ samples synthesized by various techniques are summarized in Table 2 . The specific surface values of CFAZ nanocomposites synthesized by different technological approaches are sufficient for surface related applications. The iron oxides transferred into coal fly ash zeolite-based nanocomposites from the raw CFAZ are Hematite and Magnetite phases, while when a preliminary fusion stage is applied upon their synthesis, Hematite is the only iron-containing crystalline phase because surface and bulk oxidation of magnetite to hematite occurs under the thermal heating [25]. CFAZ synthesized by ultrasonic-assisted FH contain mainly of ionic forms of the iron [26]. The simultaneous presence of $\mathrm{Fe}^{2+} / \mathrm{Fe}^{3+}$ in CFAZ stipulates their catalytic performance and adsorption ability.

\section{Application of coal ash zeolite-based nanocomposites for substitution of CRMs}

\subsection{Fluid cracking and volatile organic compounds oxidation catalysts}

The largest application of light rare earth critical raw materials is in fluid cracking catalysis directed to the petroleum industry. The most used catalysts are zeolites doped with $\mathrm{La}$ and $\mathrm{Ce}$ to increase their activity and stability. Regarding their chemical composition CFAZ contain in their composition La and Ce transferred from the raw CFA. It has been established that rare earth 
Table 2. Surface parameters of CFAZ nanocomposites.

\begin{tabular}{llllllllll}
\hline Samples & \multicolumn{10}{c}{ Surface parameters } \\
\cline { 2 - 10 } & $\begin{array}{l}S_{\mathrm{BET}}, \\
\mathrm{m}^{2} / \mathrm{g}\end{array}$ & $\begin{array}{l}S_{\text {micro, }} \\
\mathrm{m}^{2} / \mathrm{g}\end{array}$ & $\begin{array}{l}S_{\text {external, }} \\
\mathrm{m}^{2} / \mathrm{g}\end{array}$ & $\begin{array}{l}V_{\text {total }}, \\
\mathrm{cm}^{3} / \mathrm{g}\end{array}$ & $\begin{array}{l}V_{\text {micro, }}, \\
\mathrm{cm}^{3} / \mathrm{g}\end{array}$ & $\begin{array}{l}V_{\text {meso }}, \\
\mathrm{cm}^{3} / \mathrm{g}\end{array}$ & $\begin{array}{l}d_{\text {micro, }} \\
\mathrm{A}\end{array}$ & $\begin{array}{l}d_{\text {meso, }} \\
\mathrm{A}\end{array}$ & $\begin{array}{l}Y, \\
\text { wt\% }\end{array}$ \\
\hline $\mathrm{FH}$ & $265-490$ & $137-335$ & $107-166$ & $0.25-0.31$ & $0.06-0.13$ & $0.14-0.19$ & 14 & $42-49$ & $50-90$ \\
$\mathrm{HA}$ & $165-280$ & $70-190$ & $80-95$ & $0.17-0.21$ & $0.03-0.08$ & $0.13-0.14$ & $13-14$ & $47-52$ & $30-50$ \\
$\mathrm{AA}$ & $227-285$ & $166-208$ & $61-77$ & $0.17-0.24$ & $0.05-0.11$ & $0.12-0.15$ & 14 & $56-59$ & $40-52$ \\
\hline
\end{tabular}

$S_{\mathrm{BET}}-$ BET specific surface area; $S_{\text {micro }}-$ Specific surface described by micropore; $S_{\text {external }}-$ Specific external surface of particles; $V_{\text {total }}$ - Total pore volume; $V_{\text {micro }}$ - Specific volume described by micropores; $V_{\text {meso }}-$ specific volume determined by mesopores; $d_{\text {micro }}-$ average micropore diameter; $d_{\text {meso }}$ - average mesopore diameter; $Y$ - Yield of the zeolites phases.

elements migrate to the smaller cages of the super lattice zeolites of FAU type upon their crystallization forming bridges with framework oxygen atoms stabilising the zeolite structure [27]. Hydrolysis reactions taking place over the rare earth cations generate additional Brønsted acidity exceeding their activity. The most commonly used in practice catalyst for volatile organic compounds (VOCs) oxidation are noble metals $\mathrm{Pt}$ and $\mathrm{Pd}$ frequently alloyed with other CRMs, such as Ru, Rh and Ir [28,29]. Other CRMs-based catalysts are also widely used, mostly containing oxides of Co, V and W. Suitable carriers are porous materials with a specific surface area between 150 and $300 \mathrm{~m}^{2} / \mathrm{g}$, which are characterized by sufficient adsorption ability to attract the molecules of the reactants to the active sites, chemical inertness and thermal stability. These requirements are met by metal-containing zeolites, which become the most preferred supports substituting successfully CRMs-containing materials, such as niobia and alumina stabilized by $\mathrm{La}, \mathrm{Ce}, \mathrm{Mg}$. Metal-containing zeolites are characterized by micro-mesoporous texture, defined framework, acidic Brønsted centers, which in themselves give catalytic activity. Three-dimensional frame-work of coal ash zeolites allows fine and uniform distribution of metal active centers. CFAZ nanocomposites act as effective catalyst for the total oxidation of VOCs due to the presence of $\mathrm{Fe}^{3+/} \mathrm{Fe}^{2+}$ active centers formed upon their synthesis by the transfer of Hematite, Magnetite and ionic forms of iron from the raw fly ash. Their catalytic activity can be further improved by post-synthesis modification by non-CRMs containing metal oxide nanoparticles, such as $\mathrm{CuO}$ [22]. Examples on the catalytic activity of $\mathrm{CFAZ}$ nanocomposites and $\mathrm{CuO}$-modified CFAZ nanocomposites against the total oxidation of toluene are presented in Figure 7. Evidently, CFAZ act as effective catalytic systems of integrating active centers and carrier for oxidation of VOCs and can substitute successfully CRMs-based catalysts.

$\mathrm{Pt}, \mathrm{Pl}$ and $\mathrm{Rh}$ are widely used in catalytic converters in automotive industry, which are considered to be substituted by copper- and iron-modified zeolites, which are resembled a lot of CFAZ nanocomposites [30].

\subsection{Smart protective coatings}

Sol-gel composite zeolite coatings have been studied as anti-corrosion coatings due to the extended specific surface

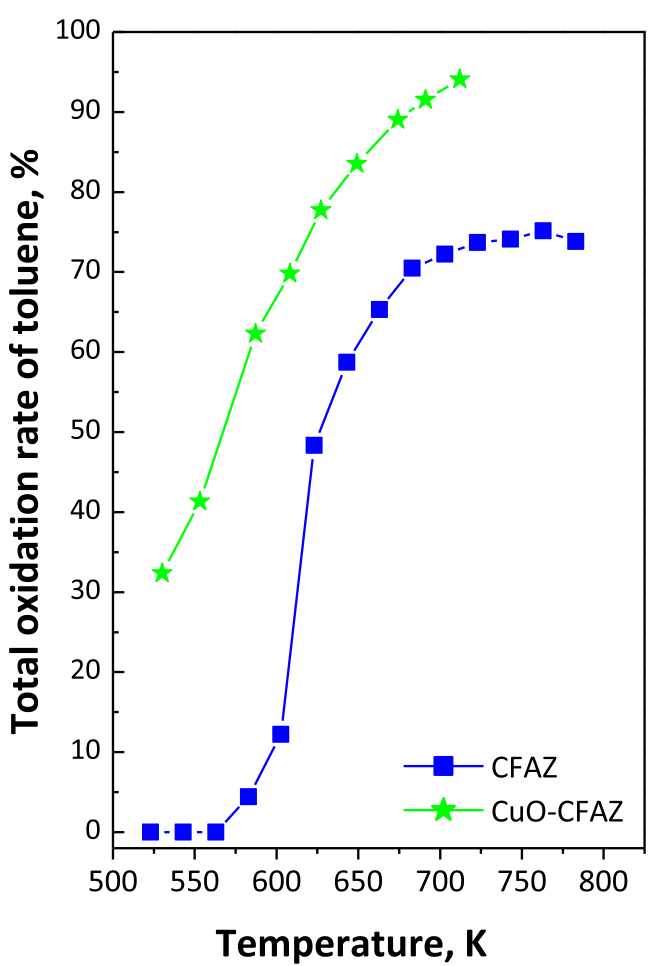

Fig. 7. Catalytic oxidation of toluene onto CFAZ nanocomposites.

area of zeolites, their molecular storage capacity and selective permeability and internal pore volume in combination with their excellent thermal stability and chemical resistance [31]. On the one hand, the zeolite coatings are an environmental compatible alternative to conventional chromate protective coatings, but from the other - their reliable protective ability will contribute to the saving CRMs, as many of them are components in metal alloys and steels. The corrosion protective behavior of composite zeolite coating is related to their barrier and self-healing properties. It has been established that adding the La-, Mo-, or Ce-enriched Na-X zeolite nanoparticles to hybrid sol-gel silane based coatings enhances their corrosion resistance. This behavior is related to the presence of rare earth ions encapsulated in the $\mathrm{Na}-\mathrm{X}$ zeolite particles, that are released in the surface of coatings 
Table 3. Chemical resistance tests.

\begin{tabular}{llll}
\hline Sample & \multicolumn{3}{c}{$\mathrm{pH}$ values } \\
\cline { 2 - 4 } & $\mathrm{pH}=0.5(\mathrm{HCl})$ & $\mathrm{pH}=7(\mathrm{NaCl})$ & $\mathrm{pH}=12(\mathrm{NaOH})$ \\
\hline Coated with FAU $(\mathrm{Na}-\mathrm{X})$ & $\Delta G=1.3 \times 10^{-4} \mathrm{~g} / \mathrm{min}$ & No corrosion & No corrosion \\
Oxidation coated stainless steel & $\Delta G=0.2 \times 10^{-4} \mathrm{~g} / \mathrm{min}$ & No corrosion & $\Delta G=1.3 \times 10^{-5} \mathrm{~g} / \mathrm{min}$ \\
\hline
\end{tabular}
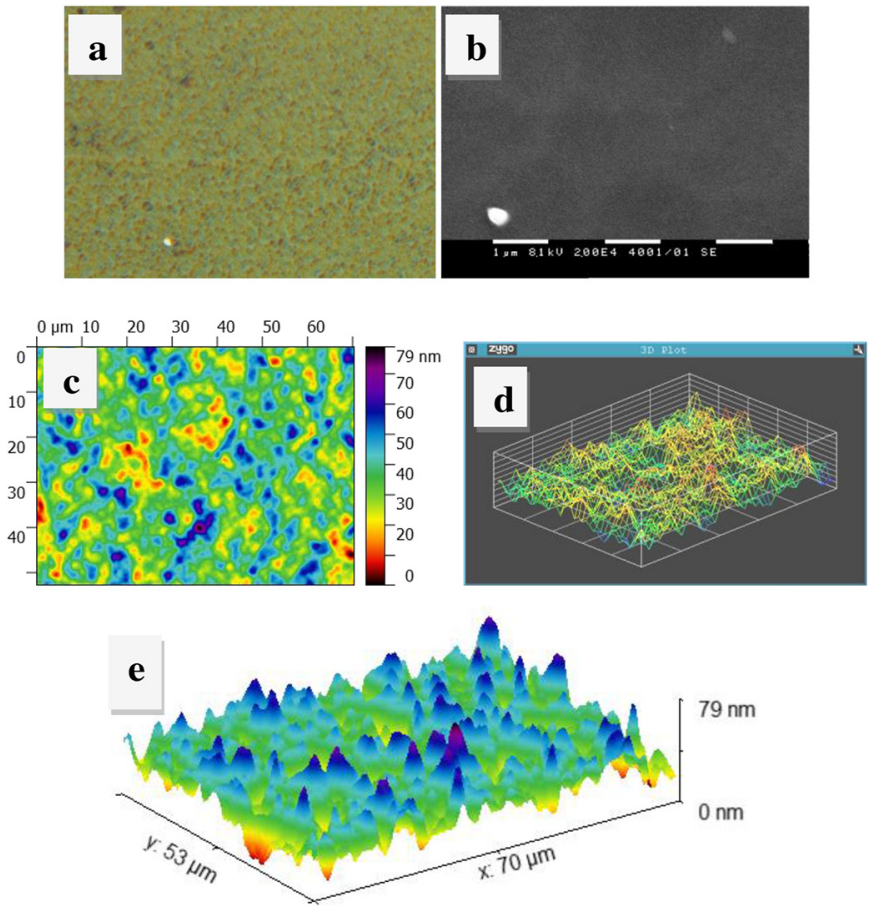

Fig. 8. Morphological and topological images of CFAZ nancomposite coatings: SEM images (a, b), AFM profilograms: topview (c), three-dimensional view (d), cross-section view (e).

taking by ion-exchange the species that cause the corrosion process. We can suppose that CFAZ will possess excellent anti-corrosion properties without any subsequent modification, because of the presence of rare earth elements in their composition, as can be seen in Table 1.

In Figure 8 results from morphological studies of sol-gel deposited coal fly ash zeolite nanocomposite coatings are demonstrated. SEM micrographs obtained by an apparatus Jeol Superprobe 733 scanning electron microscope reveal densely and uniform coatings with good surface coverage (Fig. 8a,b). AFM images, received by a Zygo Optical Profiler at a standard magnification of 50X, show nanocrystallinity of the coatings with an average thickness about $40 \mu \mathrm{m}$ (Fig. 8c-e). Sol-gel in situ deposition of zeolite films is a proven technology for processing of coatings with good adhesion with metal substrates and effective binding of layer to support interface [31,32]. Zeolites nanoparticles can be used as anti-corrosive protectors by incorporating them as fillers in polymer matrixes, so called composite zeolite coatings, acting as nano-containers hosting corrosion inhibitors [31,33]. However, CFAZ layers can be considered as nanocomposites themselves because of the dispersion of metal oxides in their structural frameworks. In confirmation of our expectations, corrosion resistance of coal ash zeolite nanocomposite coatings deposited onto reactor class austenitic steel AISI 321 (1.4541) was tested in strong aggressive media in comparison to the specimens protected by oxidation $\mathrm{NiFe}_{3-x} y \mathrm{Cr}_{y} \mathrm{O}_{4}$ layer formed under the operation of the structural material in a working environment. The results are summarized in Table 3 . Evidently, the CFAZ nanocomposite coating possesses excellent anti-corrosion properties in strong alkaline media, since no mass loss $(\Delta G, \mathrm{~g} / \mathrm{min})$ from the surface of the material was measured. This observation evidences that the zeolites derived from the wastes are comparable in chemical resistance to their pure synthetic counterparts. The corrosion resistance of zeolite-based coatings is related with their barrier properties associated with the ability to slow the diffusion of corrosive particles through the coating to the metal surface, as well as to encapsulate metal ions in their volume. In addition, zeolites themselves act as corrosion inhibitors due to their surface ability to react with hydroxyl ions $\left(\mathrm{OH}^{-}\right)$from the contact media forming silanol groups (Si-OH), and thus act as a buffer to compensate the excess of alkalinity or as a trap for $\mathrm{OH}^{-}$-ions produced by a cathodic electrochemical reaction. The high protective properties of zeolite coatings in alkaline environments is associated with the formation of a protective densely aluminum layer deposited as a corrosion product by the interaction of the zeolite coating with the electrolyte solution. Also, at high $\mathrm{pH}$ values the aluminate ions $\left(\mathrm{AlO}_{2}{ }^{-}\right)$released from the zeolite can bind ions of the metal corrosion to the formation of insoluble hydrated metal aluminates, which are deposited as a passivation layer on the surface, stopping further corrosion [34]. The main mechanisms of anti-corrosion performance of zeolite nanocomposite coating are demonstrated schematically in Figure 9.

Further, the zeolite nanocomposite layers can be doped with antimicrobial, inhibitor and healing substances due to their ion-exchange and adsorption ability for improvement of their protective functionalities [31]. CFAZ nanocomposites possess the advantages of micro-mesoporous materials and can host molecules with variety of sizes.

\subsection{Carbon capture technologies}

The mitigation of the global warming and climate change requires reliable technological decisions to reduce the concentration of atmospheric carbon dioxide $\left(\mathrm{CO}_{2}\right)$, considered as main anthropogenic greenhouse gas. The main emitters of $\mathrm{CO}_{2}$ into the atmosphere are the thermal power plants supplied by fossil fuels (coal, oil, natural gas). Different approaches have been considered to reduce the 


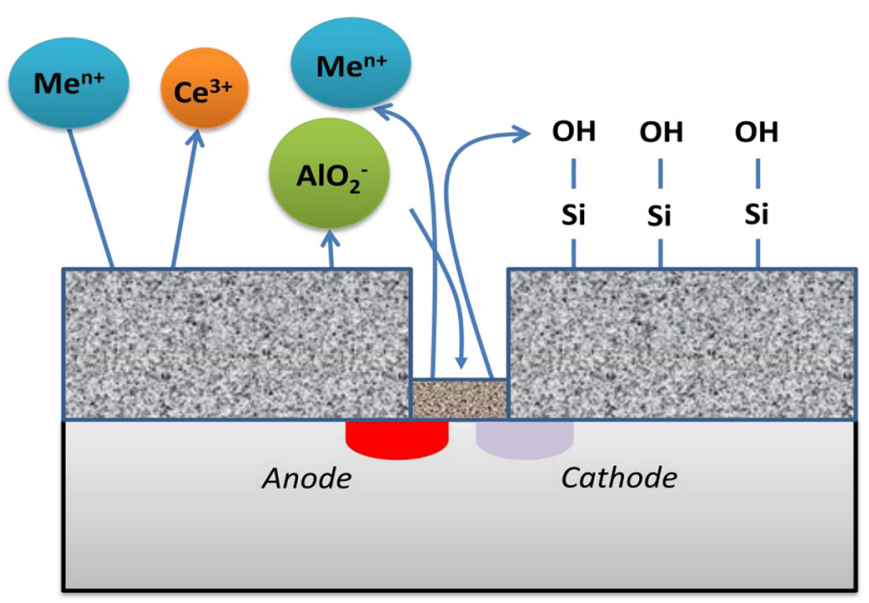

Fig. 9. Mechanisms of corrosion protection of zeolite nanocomposite coatings.

green-house gas emissions, such as: improvement of the energy efficiency of power plants, increase of the yield of low-carbon fuels, deployment of renewable energy sources: solar, wind, hydro-, bio- and geo-energy; production of hydrogen fuels; development of new generation Nuclear Power Plants; implementation of $\mathrm{CO}_{2}$ capture, utilization and storage (CCUS) technologies to power plants.

CCUS technologies are considered as the most effective to reduce $\mathrm{CO}_{2}$ emission from energy production; however their commercial affordability is the main critical point for their wide implementation. The essence of CCUS is demonstrated in Figure 10. CCUS are based on $\mathrm{CO}_{2}$ separation from exhaust gases and its concentration in a pure of other components flow, which is subsequently compressed below the $\mathrm{CO}_{2}$ triple point of liquefying. Further, the liquid $\mathrm{CO}_{2}$ is utilized as a raw stuff for chemistry, enhanced oil recovery, as a cooler or it is stored underground.

CCUS are developed in three main technological approaches, so called post-combustion capture, precombustion capture and oxy-fuel combustion [35]. The principles of these technological decisions are illustrated in Figure 11.

Post-combustion capture is an "end of pipe" technology based on traditional combustion process, at which the carbon capture unit is installed as the last cleaning system of the flue gas before they to be emitted through the chimney. Pre-combustion capture requires gasification of the fuel to produce synthetic combustible gas with high caloricity suitable for incineration in gas turbines. Gasification eliminates some of the flue gas components that interfere with the $\mathrm{CO}_{2}$ separation. Oxy-fuel is a technology at which the combustion is carried out by using pure oxygen instead of air for the combustion of fuels, omitting the nitrogen oxides from the flue gases. In the case of natural gas, the only combustion by-products are $\mathrm{CO}_{2}$ and water vapors, which are easily separated by condensation. However, when solid fuels are used other components in flue gases are also observed, such as sulfur and nitrogen oxides, solid particles, etc. Oxy-fuel is considered as a leader among the CCUS technologies. However, the

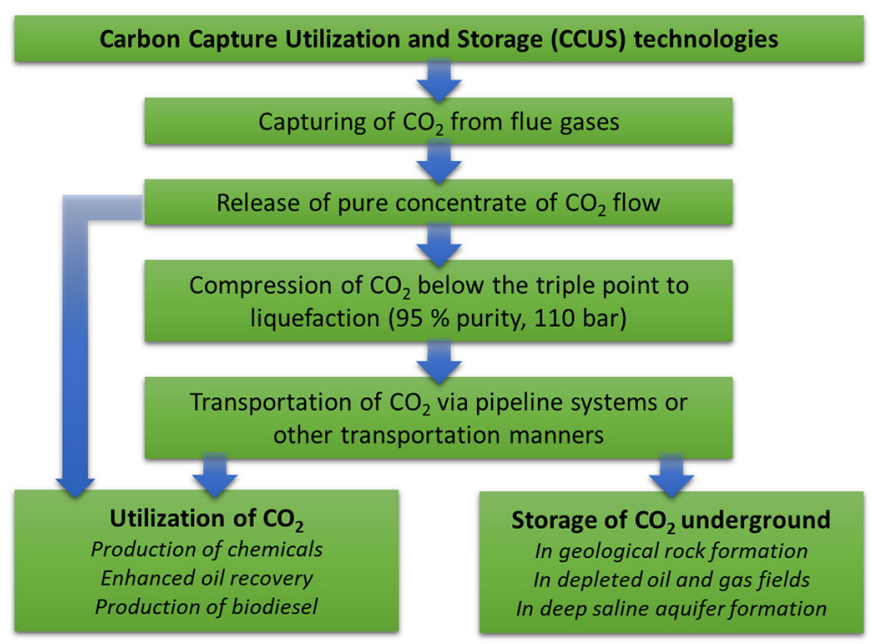

Fig. 10. General technological chain of CCUS.

long-term operation, safety and reliability of such a plant puts serious demands on the structural materials because they are exposed to the synergy affect of the high temperature, strong oxidation, deposits from solid fuels, moisture and acidic gases. Increased concentration of $\mathrm{SO}_{3}$ and water vapors in oxy-fuel combustion increases significantly the acid dew point and enhances the risk of low temperature corrosion in cool parts of the systems. Oxygen for oxy-fuel combustion is produced by cryogenic air separation which is a highly energy intensive process consuming $10-15 \%$ from the output power of the plant resulting in significant energy costs. Therefore, new generation high efficient air separation units are developed for oxygen supply. As an emerging alternative for less energy intensive technology is considered the air separation using oxygen-conducting ceramic membranes (ionic transport membranes). Among the number of studied membrane materials, perovskites containing Co or La are the most promising due to their particular ionic conductivity and thermal stability [36]. In the oxy-fuel condition high temperature corrosion at superheated surfaces is also accelerated due to the oxidative attack, sulfatization and carbonization reactions of the metal surfaces. Corrosionresistant duplex and super-duplex (high $\mathrm{Cr}$ ) stainless steels, stabilized austenitic steels and high-nickel alloys are mainly considered as main structural material for boiler tubes, super heaters, air heaters, flue gas transportation pipes, and super-austenite alloys for flue gas condensers. Increased requirements for corrosion resistance of the structural materials for oxy-fuel technologies will increase the needs for CRMs, such as V, W and Nb, and the cost of structural materials in general.

The capturing of $\mathrm{CO}_{2}$ from flue gases is the most important technological step on which the reliability, efficiency and economic performance of the post-combustion capture processes are dependent. The most spread carbon capture technology is based on the chemisorption of $\mathrm{CO}_{2}$ from amine-based solutions by scrubbing [37] However, because of the harmful characteristics of the amine-based substances and the significant energy demands for their regeneration, porous solids have also 


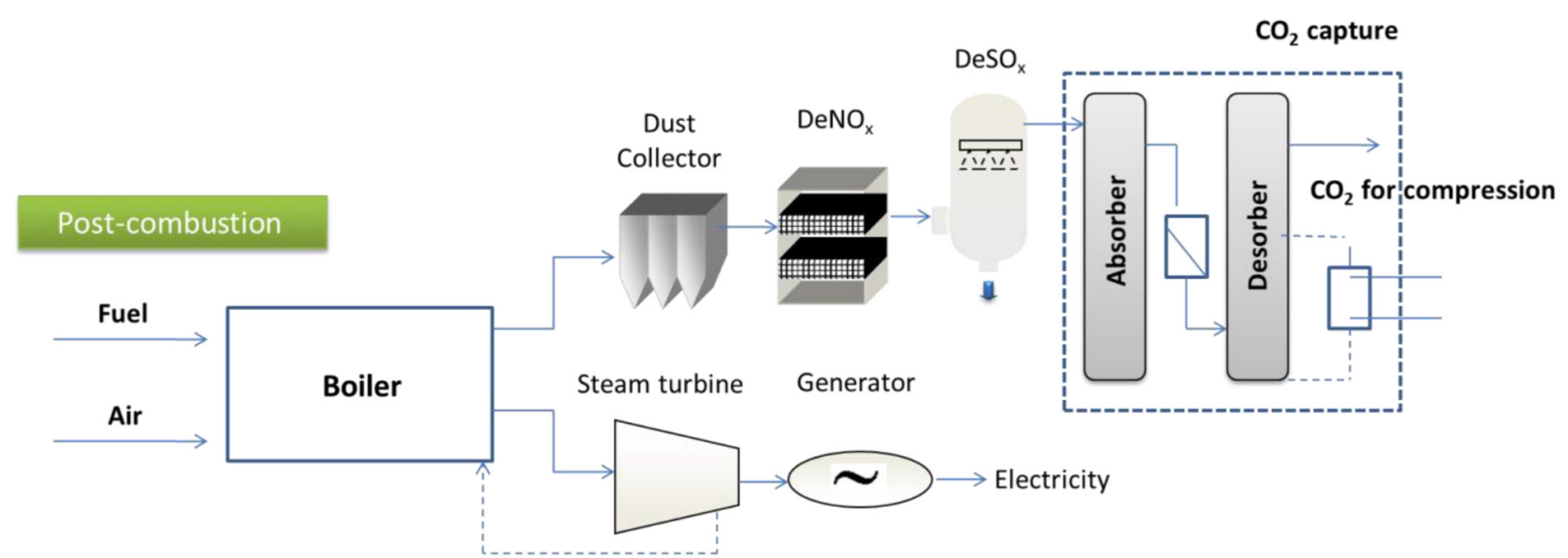

\section{Pre-combustion}

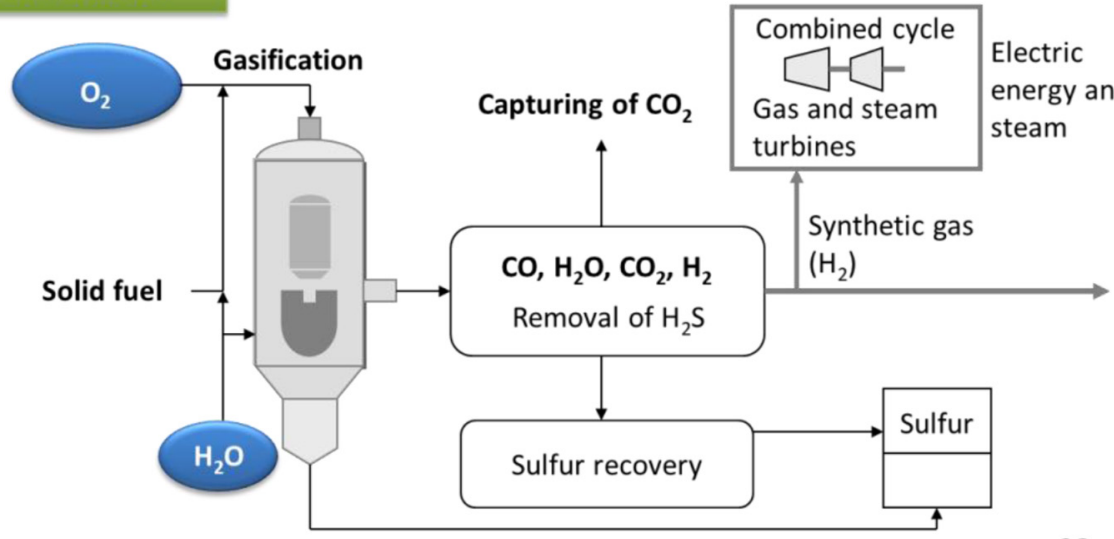

$\mathrm{CO}_{2} \longrightarrow$ Compressing

Oxy-fuel combustion

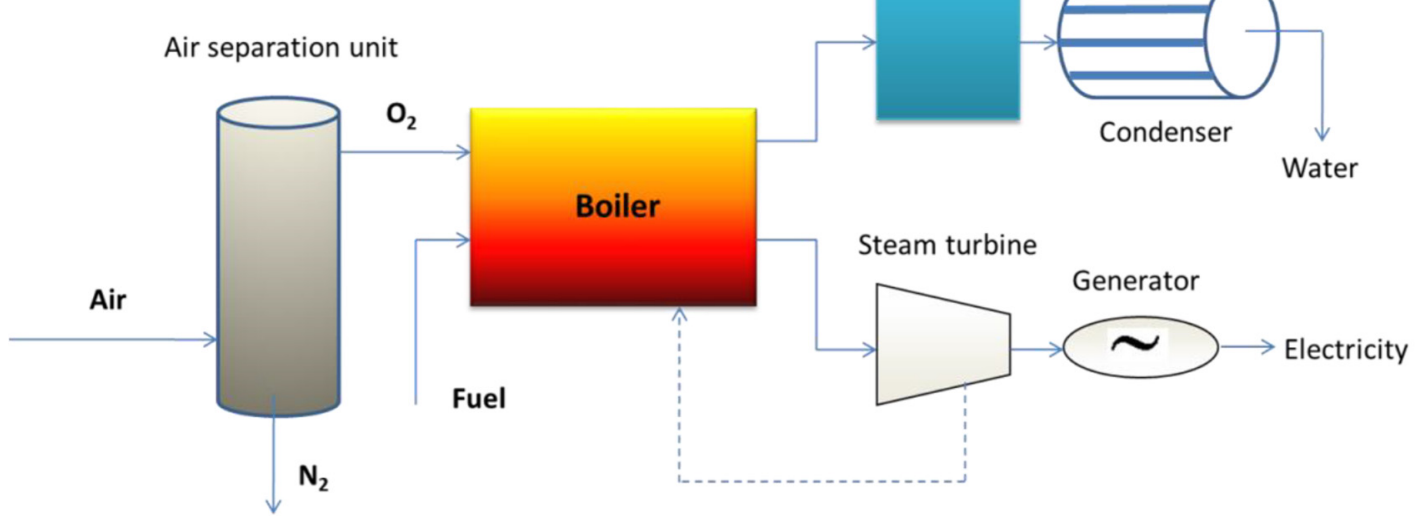

Fig. 11. Technological approaches of CCUS.

been studied as potential adsorbents for CCUS [38]. CFAZ nanocomposites reveal great potential to be applied as carbon capture media obeyed by their favorable surface characteristics and embedded particles of iron oxides in their framework $[26,39]$. The presence of iron oxides contribute to higher instauration of the surface bonds of CFAZ nanocomposites which results in stronger dipolequadrupole electrostatic interactions with $\mathrm{CO}_{2}$ molecules facilitating their polarization and capturing [40,41]. Typical equilibrium adsorption isotherms of $\mathrm{CO}_{2}$ onto CFAZ nanocomposites measured at $0{ }^{\circ} \mathrm{C}$ are presented in Figure 12. The equilibrium adsorption capacity of these materials toward $\mathrm{CO}_{2}$ reaches $140 \mathrm{mg} / \mathrm{gCFAZ}$, while their capture capacity in flows is $95 \%$ from the equilibrium values. It was established that the regeneration of $\mathrm{CFAZ}$ takes place at low temperatures of $50^{\circ} \mathrm{C}$ due to their mixed 


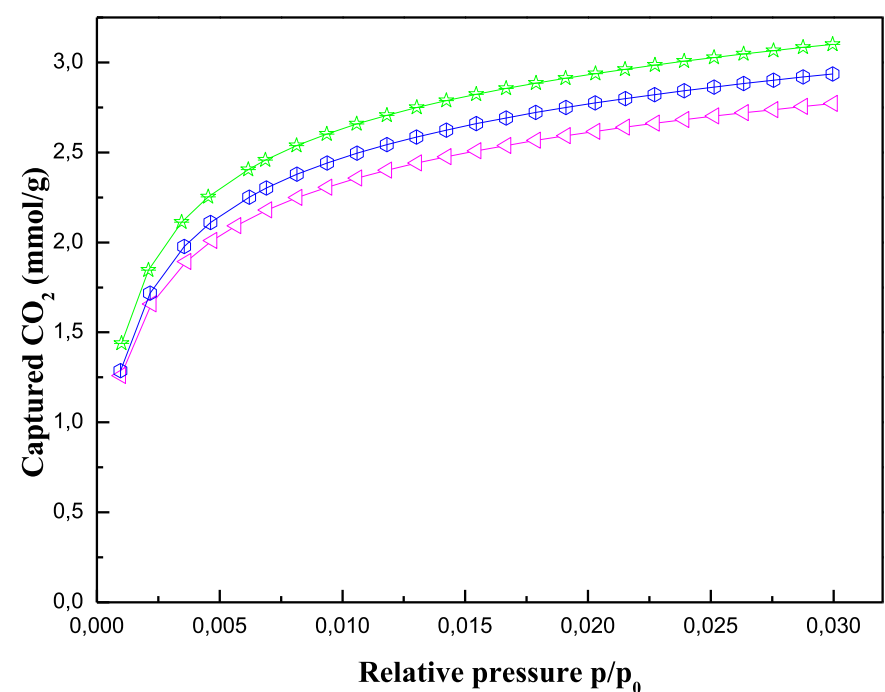

Fig. 12. Equilibrium adsorption isotherms of $\mathrm{CO}_{2}$ onto $\mathrm{CFAZ}$.

micro-mesoporosity which is of great advantage for reducing the energy costs for the CCUS technology. Model studies on $\mathrm{CO}_{2}$ adsorption on coal ash zeolites are an important step in the transfer of laboratory results to pilot and full-scale installations. It has been observed that the experimental adsorption isotherm of the equilibrium $\mathrm{CO}_{2}$ adsorption onto CFAZ are in good agreement with the Langmuir model for the pressure range up to $100 \mathrm{kPa}$, which are the typical pressure values for the exhaust flue gases in TPPs [42]. Input data for the design of adsorption plants are not only the equilibrium adsorption capacities, but also the dynamic parameters of the process. The kinetics of the adsorption process is determined by the rate of the several stages: transfer of the gas molecules to the solid surface through the boundary diffusion layer, diffusion into the adsorbent particles, and adsorption. Model studies of the dynamic adsorption in the $\mathrm{CO}_{2}-\mathrm{CFAZ}$ system has revealed a good correlation of the experimental breakthrough curves with the linear driving force model (LDF) [42].

The development of effective and inexpensive adsorbents of carbon dioxide for post-combustion carbon capture will contribute to lower demands of CRMs because of its competitiveness to the oxy-fuel combustion.

Moreover, CRMs are important ingredients of materials for the other perspective alternatives of low-carbon energetic, such as wind turbines (Nd, Dy, Pr), electric vehicles (Co, Graphite) and solar cells (Ge, Si, Ga, In) [43].

\subsection{Water treatment}

Phosphate rocks considered as CRM are used for production of detergents mainly in the form of sodium tripolyphosphate. The main function of detergents is to reduce water hardness in industrial boilers, and dishwasher and washing machines for the home use. It has been established that the based detergents can be substituted cost-effectively by zeolites due to their water softening performance and non-toxic characteristics. CFAZ have
Table 4. Reduction of hardness of drinking waters.

\begin{tabular}{lll}
\hline Sample & \multicolumn{2}{c}{ Hardness values, mg-eq/1 } \\
\cline { 2 - 3 } & $H_{\text {initial }}$ & $H_{\text {final }}$ \\
\hline CFAZ Linde A & 0.875 & 0.615 \\
CFAZ Faujasite Na-X & 0.875 & 0.350 \\
\hline
\end{tabular}

been widely studied as adsorbents and ion-exchangers for water treatment technologies $[44,45]$. The softening effect of CFAZ nanocomposites of Linde and Faujasite types were studied revealing between $30 \%$ and $60 \%$ of hardness reduction from the levels typical for drinking waters (Tab. 4). CFAZ nanocomposites can be prepared as magnetic adsorbents and ion-exchangers which allow them to be removed easily from treated waters by applying magnetic field [46].

\section{Conclusions}

Coal fly zeolites-based nanocomposites processing is based on the alkaline conversion of coal fly ash by simple and industrially feasible techniques, which represents valuable and smart approach for utilization of the abundant resource of these solid wastes. CFAZ nanocomposites can be obtained as powders or thin films with controllable phase composition and morphology. These materials are characterized by a mixed micro-mesoporous structure, finely distributed iron oxides and variety of metal specifies transferred from the raw coal ash. Among the accompanying components there are elements in their composition attributed to the group of the critical raw materials. The presence of CRMs in the CFAZ nanocomposite matrixes benefits some of their applications. CFAZ nanocomposite can be considered as a cost-efficient alternative of CRMs in oxidative catalysis, smart-protective coatings and water detergents. Coal fly zeolites-based nanocomposites behave strong adsorption ability toward carbon dioxide and energy efficient recovery and are promising candidates for postcombustion carbon capture technologies. The industrial priority of post-combustion carbon capture over the oxyfuel combustion energy plants will provide economical use of critical raw materials.

\section{Implications and influences}

The potential of coal fly ash zeolites have been explored for the first time from the point of view of their application for substitution of critical raw materials. This study will contribute to the deepening of research on the smart utilization of coal fly ash for processing of materials with high practical values and great contribution for the environmental protection, preservation of natural resources and critical raw material saving. In the present manuscript for the first time are provided results on the development of smart anti-corrosion coatings from coal fly ash nanocomposites which is opening up a wide horizon for research in their optimization. 
The financial support of Bulgarian National Science Fund under the projects DN 17/18 and the bilateral research project under Grant DNTS Slovak Republic 01/6 is highly appreciated.

\section{References}

1. International Energy Association, IEA, Coal 2018: Analysis and Forecasts to 2023, Marker Report Series, 2018, ISBN 978-92-64-30680-6.

2. Eurostat,Coal production and consumption statistics, 2019, www.ec.europa.eu

3. Eur-lex, Document 52011IE1597, Opinion of the European Economic and Social Committee on 'The processing and exploitation, for economic and environmental purposes, of industrial and mining waste deposits in the European Union' (own-initiative opinion), Official Journal of the European Union, (2012/C 24/03) 2012

4. J. Toleffson, Innovative zero-emissions power plants begins battery of tests, Nature $\mathbf{5 5 7}$ (2018) 622-623

5. T. Pitso, Clean coal technology adaptability and R and D support for efficiency and sustainability, in: Green Technologies to Improve the Environment on Earth, edited by M. Pachesco (IntechOpen, 2019), doi: 10.5772/inte chopen. 81605

6. European Coal Combustion Products Association, ECOBA, Production and Utilisation of CCPs in 2016 in Europe

7. S.V. Vassilev, R. Menendez, Phase-mineral and chemical composition of coal fly ashes as a basis for their multicomponent utilization. 4. Characterization of heavy concentrates and improved fly ash residues, Fuel 84 (2005) 973-991

8. R.S. Blissett, N.A. Rowson, A review of the multi-component utilisation of coal fly ash, Fuel (2012) 1-23

9. ASTM C618-19 Standard Specification for Coal Fly Ash and Raw or Calcined Natural Pozzolan for Use in Concrete

10. X. Querol, N. Moreno, J.C. Umaña, A. Alastuey, E. Hernández, A. López-Soler, F. Plana, Synthesis of zeolites from coal fly ash: an overview, Int. J. Coal Geol. 50 (2002) 413-423

11. J.P. Brassel, T.V. Ojumu, L.F. Petrik, Upscaling of zeolite synthesis from coal fly ash waste: current status and future outlook, in: Zeolites - useful minerals, edited by C. Belviso (IntechOpen, 2016), doi:10.5772/63792

12. R.L. Bedard, Synthesis of zeolites and manufacture of zeolitic catalysts and adsorbents, in Zeolites in Industrial Separation and Catalysis, edited by S. Kulprathipanja (J. Whiley \& Sons, Inc., 2010), doi:10.1002/9783527629565

13. E. Kianfar, Nanozeolites: synthesized, properties, applications, J. Sol-Gel Sci. Technol. 91 (2019) 415-429

14. J. Caro, Zeolites and mesoporous materials as advanced functional material, Stud. Surface Sci. Catal. 54 (2004) 80-93

15. Eur-lex, European Commission, Document 52017DC0490, Communication from the commission to the European Parliament, the Council, the European Economic and Social Committee and the Committee of the regions on the 2017 list of Critical Raw Materials for the EU, COM/2017/0490, 2017

16. P. Ferro, F. Bonollo, Materials selection in a critical raw materials perspective, Mater. Des. 177 (2019) 107848

17. D. Friedman, T. Masciangioli, S. Olson, Replacing Critical Materials with Abundant Materials, in: The role of chemical sciences in finding alternatives to critical resources (The National Academic Press, Washington D.C., 2012), pp. 2128, ISBN: 978-0-309-25429-8
18. M. Buchert, S. Degreif, W. Bulach, D. Schüler, S. Prakash, M. Möller, A. Köhler, S. Behrendt, R. Nolte, A. Röben, Substitution as a strategy for reducing the criticality of raw materials for environmental technologies, in Resource Conservation, Material Cycles, Minerals and Metal Industry, edited by F. Müller (German Environment Agency, Umweltbundesamt Publ., 2019), pp. 1-25, ISSN $1862-4804$

19. D. Zgureva, S. Boycheva, Synthesis of highly porous microand nanocrystalline zeolites from aluminosilicate by-products, in Nanoscience Advanced in CBRN Agents Detection, Information and Energy, Springer Security Science for Peace and Security Series - A: Chemistry and Biology, edited by P. Petkov, D. Tsiulyanu, W. Kulisch, C. Popov (2015) pp. 199-204

20. S. Boycheva, I. Marinov, S. Miteva, D. Zgureva, Conversion of coal fly ash into nanozeolite Na-X by applying ultrasound assisted hydrothermal and fusion-hydrothermal alkaline activation, Sustain. Chem. Pharm. 15 (2020) 100217

21. N. Murayama, H. Yamamoto, J. Shibat, Mechanism of zeolite synthesis from coal fly ash by alkali hydrothermal reaction, Int. J. Miner. Process. 64 (2002) 1-17

22. S. Boycheva, D. Zgureva, M. Václavíková, Y. Kalvachev, H. Lazarova, M. Popova, Studies on non-modified and copper-modified coal ash zeolites as heterogeneous catalysts for VOCs oxidation, J. Hazard. Mater. 361 (2019) $374-382$

23. L. Bonaccorsi, E. Proverbio, Synthesis of thick zeolite 4A coatings on stainless steel, Micropor. Mesopor. Mater. 74 (2004) 221-229

24. L. Li, B. Xue, J. Chen, N. Guan, F. Zhang, D. Liu, H. Feng, Direct synthesis of zeolite coatings on cordierite supports by in situ hydrothermal method, Appl. Catal. A 292 (2005) 312-321

25. S. Boycheva, D. Zgureva, V. Vassilev, Kinetic and thermodynamic studies on the thermal behavior of fly ash from lignite coals, Fuel 108 (2013) 639-646

26. M. Popova, S. Boycheva, H. Lazarova, D. Zgureva, K. Lázárd, A. Szegedi, VOCs oxidation and $\mathrm{CO}_{2}$ adsorption on dual adsorption/catalytic system based of fly ash zeolites, Catal. Today https://doi.org/10.1016/j.cattod.2019.06.070

27. E. Falabella, F. Trigueiro, Z. Fatima, The role of rare earth elements in zeolites and cracking catalysts, Catal. Today 218-219 (2013) 115-122

28. H. Huang, Y. Xu, Q. Feng, D.Y.C. Leung, Low temperature catalytic oxidation of volatile organic compounds: a review, Catal. Sci. Technol. 5 (2015) 2649-2669

29. A. Rusu, E. Dumitriu, Destruction of volatile organic compound by catalytic oxidation, Environ. Eng. Manag. J. 2 (2003) 273-302

30. S. Recknagel, M. Michaelis, Certification of the mass fraction of $\mathrm{Pt}, \mathrm{Pd}$ and $\mathrm{Rh}$ in a used car catalysts reference material, Accred. Qual. Assur. 14 (2009) 277-280

31. L. Calabrese, E. Proverbio, A brief overview on the anticorrosion performances of sol-gel zeolite coatings, Coatings 9 (2019) 409, doi:10.3390/coatings9060409

32. R. Cai, Y. Yan, Corrosion-Resistant Zeolite Coatings, Corrosion 64 (2008) 271-278

33. G. Zhang, L. Wu, A. Tang, X. Ding, B. Jiang, A. Atrens, F. Pan, Smart epoxy coating containing zeolites loaded with Ce on a plasma electrolytic oxidation coating on Mg alloy AZ31 for active corrosion protection, Prog. Org. Coat. 132 (2019) $144-147$ 
34. L. Calabrese, L. Bonaccorsi, D.D. Pietro, E.E. Proverbio, Effect of process parameters on behaviour of zeolite coatings obtained by hydrothermal direct synthesis on aluminium support, Ceram. Int. 40 (2014) 12837-12845

35. D.Y.C. Leung, G. Caramanna, M.M. Maroto-Valer, An overview of current status of carbon dioxide capture and storage technologies, Renew. Sust. Energ. Rev. 39 (2014) 426-443

36. T. Lockwood, Developments in oxyfuel combustion of coal, IEA Clean Coal Centre, 2014, ISBN: 978-92-9029-561-7

37. G.T. Rochelle, Amine scrubbing for $\mathrm{CO}_{2}$ capture, Science 325 (2009) 1652-1654

38. A. Samanta, A. Zhao, G.K.H. Shimizu, P. Sarkar, R. Gupta, Post-combustion $\mathrm{CO}_{2}$ capture using solid sorbents: a review, Ind. Eng. Chem. Res. 51 (2012) 1438-1463

39. Yu. Kalvachev, D. Zgureva, S. Boycheva, B. Barbov, N. Petrova, Synthesis of carbon dioxide adsorbents by zeolitization of fly ash, J. Therm. Anal. Calorim. 122 (2015) 101-106

40. K.C. Chanapattharapol, S. Krachuamram, S. Youngme, Study of $\mathrm{CO}_{2}$ adsorption on iron oxide doped MCM-41, Micropor. Mesopor. Mat. 245 (2017) 8-15

41. J.A. Rodriguez, A quantum chemical study of the adsorption of carbon dioxide and hydroxyl on copper and zinc oxide surfaces and hydroxyl on platinum surfaces, Langmuir 4 (1988) 1006-1020
42. D. Zgureva, S. Boycheva, Experimental and model investigations of $\mathrm{CO} 2$ adsorption onto fly ash zeolite surface in dynamic conditions, Sustain. Chem. Pharm. 15 (2020) 100222

43. R.L. Moss, E. Tzimas, H. Kara, P. Willis, J .Kooroshy, Critical Metals in Strategic Energy Technologies. Assessing Rare Metals as Supply-Chain Bottlenecks in Low-Carbon Energy Technologies, JRC Scientific and Technical Reports, EUR 2011, 24884 EN, doi: 10.2790/35600

44. D. Zgureva, S. Boycheva, D. Behunová, M. Václavíková, Coal fly ash zeolites as adsorbents for effective removal of heavy metals and dyes from contaminated waters, in 16th International Conference on Environmental Science and Technology, CEST 2019, 4-7 Septermber 2019, Rhodes, Greece

45. F. Mushtaq, M. Zahid, I.A. Bhatti, S. Nasir, T. Hussain, Possible applications of coal fly ash in wastewater treatment, J. Environ. Manag. 240 (2019) 27-46

46. S. Boycheva, S. Miteva, I. Trendafilova, D. Zgureva, M. Václavíková, M. Popova, Magnetite nanoparticles activated coal fly ash zeolites with application in waste water remediation, in 16th International Conference on Environmental Science and Technology, CEST 2019, 4-7 Septermber 2019, Rhodes, Greece

Cite this article as: Silviya Boycheva, Denitza Zgureva, Hristina Lazarova, Katerina Lazarova, Cyril Popov, Tsvetanka Babeva, Margarita Popova, Processing of high-grade zeolite nanocomposites from solid fuel combustion by-products as critical raw materials substitutes, Manufacturing Rev. 7, 22 (2020) 